\title{
COVID-19 and Guillain-Barré Syndrome: A fortuitous relationship?
}

\author{
Hector J. Piñera-Castro* \\ Institute of Basic and Preclinical Sciences “Victoria de Girón”, University of Medical Sciences of Havana, Playa, Havana, Cuba
}

\begin{abstract}
Although severe acute respiratory syndrome coronavirus 2 (SARS-CoV-2) mainly affects the respiratory system, multiple neurological manifestations have been described. Guillain-Barré syndrome (GBS) is one of those. Despite the limited existence of cases reporting the association between GBS and coronavirus disease 2019 (COVID-19), the number of publications on this subject is increasing, thus making it relevant to compile and synthesize analytically all the nascent information. The objective of this article is to describe the association between COVID-19 and GBS. SARS-CoV-2 is neuroinvasive, neurotropic, and neurovirulent, which allows it to cause neurological damage, including GBS. There have been case reports of a possible association between COVID-19 and GBS in China, the United States of America, Iran, Italy, Spain, France, Germany, and other countries. GBS is emerging as a possible neurological complication in patients with COVID-19. The current evidence does not prove the veracity of a relationship between COVID-19 and GBS, but it justifies its verisimilitude. Further studies on the topic will provide biomedical personnel with a more complete understanding of the performance of GBS in patients with COVID-19, as well as information regarding how to successfully treat it.
\end{abstract}

Key words: COVID-19. SARS-CoV-2. Guillain-Barré syndrome.

\section{COVID-19 y síndrome de Guillain-Barré: ¿una relación fortuita?}

\section{Resumen}

Aunque el coronavirus tipo 2 del síndrome respiratorio agudo grave (SARS-CoV-2) afecta principalmente al sistema respiratorio, múltiples manifestaciones neurológicas han sido descritas. El síndrome de Guillain-Barré (SGB) constituye una de estas; y pese a existir pocos reportes de su asociación con la enfermedad por coronavirus de 2019 (COVID-19), el número de publicaciones relativas al tema incrementa por día, lo cual hace que la recopilación y síntesis analítica de toda la información emergente cobren vital relevancia. El objetivo de este artículo es describir la asociación existente entre la COVID-19 y el SGB. EI SARS-CoV-2 es neuroinvasivo, neurotrópico y neurovirulento, lo cual justifica su capacidad para ocasionar trastornos neurológicos, incluido el SGB. Existen reportes de casos con posible asociación entre la COVID-19 y el SGB en China, Estados Unidos de América, Irán, Italia, España, Francia, Alemania, entre otros países. EI SGB está emergiendo como una potencial complicación neurológica en pacientes con COVID-19. La evidencia existente hasta el momento, si bien no demuestra una relación entre la COVID-19 y el $S G B$, sí justifica la verosimilitud de esta asociación. Estudios que en el futuro se realicen habrán de proporcionar un conocimiento más completo sobre el comportamiento del SGB en pacientes con COVID-19 y cómo tratarlo.

Palabras clave: COVID-19. SARS-CoV-2. Síndrome de Guillain-Barré.

\section{${ }^{*}$ Correspondence:}

Hector J. Piñera-Castro

E-mail: hectorpinera18100@gmail.com
Available online: 21-10-2020 Rev Mex Neuroci. 2020;21(5):205-214 www.revmexneurociencia.com 1665-5044/ C 2020 Academia Mexicana de Neurología A.C. Published by Permanyer. This is an open access article under the CC BY-NC-ND license (http://creativecommons.org/licenses/by-nc-nd/4.0/). 


\section{Introduction}

In December 2019, several patients with respiratory symptoms and pneumonia were notified in Wuhan (China). The causative agent was a novel coronavirus (2019-nCoV) which taxonomic designation changed to severe acute respiratory syndrome coronavirus 2 (SARS-CoV-2) on February 11, 2020. A few hours later, the disease was named coronavirus disease 2019 (COVID-19). With its ulterior increase in the number of cases and its spread throughout the globe, it was declared a pandemic by the World Health Organization on March 11, 20201.

Even though SARS-CoV-2 has been observed to mainly affect the respiratory system, some neurological disorders have been reported, such as febrile seizures, headache, dizziness, myalgia, ataxia, smell and taste disorders, encephalopathy, encephalitis, strokes, disorders of consciousness, and peripheral neuropathies. In this last category, there have been some reports of patients with Guillain-Barré syndrome (GBS) ${ }^{2-4}$.

COVID-19 is a disease for which practitioners and researchers are still learning signs/symptoms, risk factors, comorbidities, and outcomes. Although COVID-19 research is vertiginously evolving, novel findings require in-depth scrutiny before they allow us to formulate new hypotheses and draw solid conclusions. This is the circumstance of the association between COVID-19 and GBS, for which are few case reports ${ }^{5}$.

While it is true that there are not many publications on the said relationship, the unceasing increase of such numbers is a fact. This justifies the extraordinary importance of compiling, analyzing, and synthesizing all the nascent information on the topic, geared toward boosting the current diagnostic, therapeutic, and prophylactic capacities of the biomedical personnel that fights against the challenges of COVID-19 around the world. In the spirit of contributing to the achievement of such a laudable purpose, the objective of this article is to describe the association between COVID-19 and GBS.

A literature review was conducted using Google Scholar as a search engine (no time limit), with the following descriptors (and their equivalents in Spanish): COVID-19, SARS-CoV-2, GBS, and neurological complications/manifestations. The last information search was carried out on June 19, 2020. Articles from journals indexed in PubMed, ScienceDirect, Wiley \& Sons, ISI Web of Science, and Scopus were consulted. Articles that had not been peer-reviewed, duplicated articles, or those that could be biased due to the methodology followed in their elaboration were excluded from the study. Twenty-three publications with the required scientific quality were finally selected, including literature reviews, case reports, systematic reviews, letters to the editors, editorials, and clinical series. Their content was carefully analyzed and synthesized.

\section{SARS-CoV-2: neuroinvasive, neurotropic and neurovirulent}

Respiratory viruses can penetrate the central nervous system (CNS) (neuroinvasiveness), affect neurons and glial cells (neurotropism), and induce a wide range of neurological disorders (neurovirulence) ${ }^{6}$.

SARS-CoV-2 binds to the angiotensin-converting enzyme 2 (ACE2) receptor and invades the cells that express it. This receptor is present in the pneumocytes of the lower respiratory tract (main target), pulmonary parenchyma, vascular endotheliocytes, kidneys, smooth muscle, heart, testicular tissue, bowels, bone marrow, spleen, skin, adipocytes, and the CNS. Some cells, like hepatocytes, can be infected even if such receptor is absent. In the CNS, it is predominantly expressed in the cerebellum, thalamic nuclei, inferior olivary nuclei, nuclei of the solitary tract, and the ventrolateral medulla oblongata ${ }^{1,6-8}$.

Residue 394 (glutamine) in the SARS-CoV-2 receptor-binding domain is recognized by residue 31 (lysine) on the ACE2 receptor. This produces a conformational change in the spike protein of the virus that facilitates the fusion between the SARS-CoV-2 envelope and the membrane of infected cells, with the subsequent entrance of the genomic RNA of the virus to the intracellular compartment 6 .

The neurophysiopathogenic mechanisms of SARS-CoV-2 (Fig. 1) that have been cited in the literature are:

- Direct damage after neuroinvasion. SARS-CoV-2 can enter the CNS through a blood pathway (with the production of some cytokines that increase the permeability of the blood-brain barrier [BBB]), or a neuronal pathway; most evidence revolves around the second one. SARS-CoV-2 can infect nerve endings and achieve retrograde or anterograde neuronal transport mediated by motor proteins (dynein and kinesins). Through the olfactory bulb (it is suggested that this particular pathway is related to the hyposmia/anosmia described in certain patients with COVID-19), the virus can reach the brain within 7 days, where it causes an inflammatory reaction (with reactive astrogliosis and microglial activation) and 


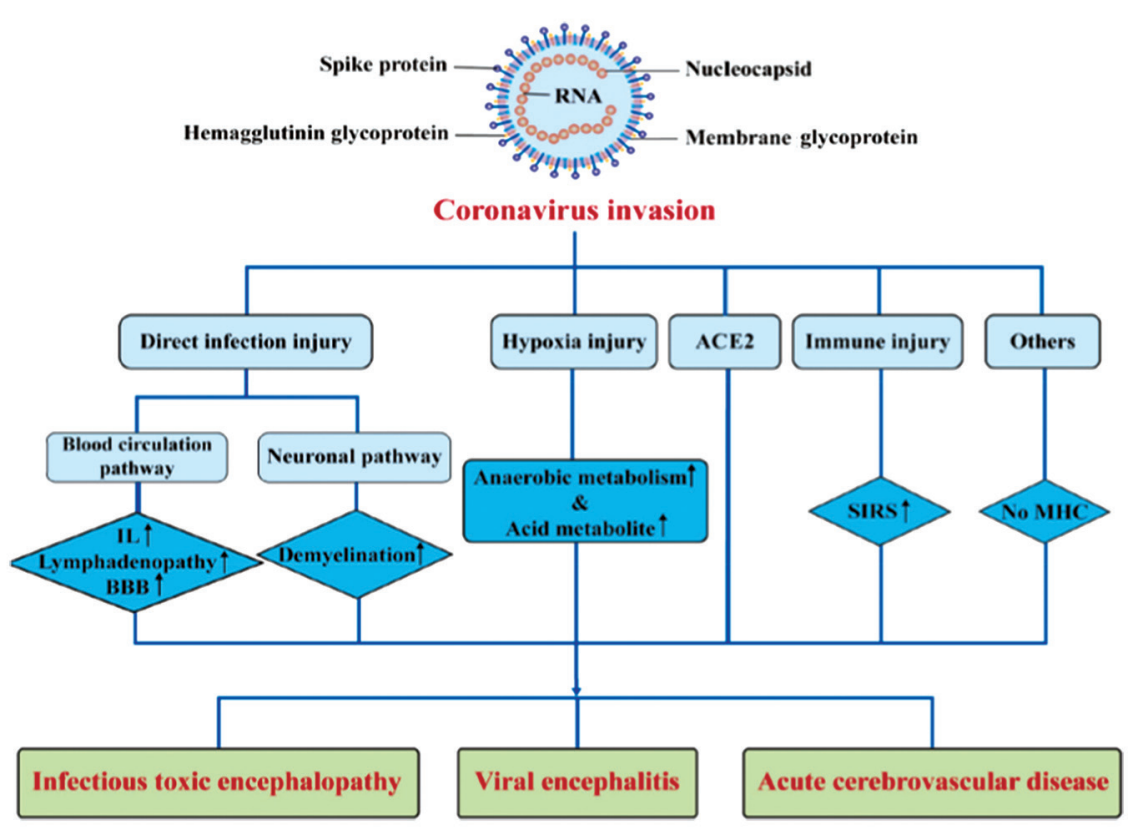

Figure 1. Pathogenesis of nervous system injury caused by coronaviruses. ACE2: angiotensin-converting enzyme 2; BBB: blood-brain barrier; IL: interleukin; MHC: major histocompatibility complex; SIRS: systemic inflammatory response syndrome (adapted from Wu et al. $2020^{\circ}$ ).

demyelination. The invasion may occur through peripheral nerves as well ${ }^{2,9-11}$.

- Hypoxic damage. When the virus proliferates in lung tissue cells, it causes diffuse alveolar and interstitial inflammatory exudation, as well as edema. These, in turn, lead to alveolar gas exchange disorders causing hypoxia in the CNS, which increases anaerobic metabolism in the mitochondria of brain cells. Accumulation of metabolic acids can cause cerebral vasodilatation, swelling of brain cells, interstitial edema, obstruction of cerebral blood flow, and even headache due to ischemia and congestion. If the hypoxia continues unabated, cerebral edema and the cerebral circulation disorder may worsen sharply. With intracranial hypertension, brain function gradually deteriorates; and drowsiness, bulbar conjunctival edema, and even coma can be observed. In addition, for patients at particular risk of developing cerebrovascular diseases, hypoxia may also induce the occurrence of acute cerebrovascular diseases such as acute ischemic stroke $\mathrm{e}^{2,9,12}$.

- Damage from a combination of neuroinflammation and hypoxia. The systemic inflammation associated with SARS-CoV-2 infection endangers the BBB integrity, which severely disturbs brain homeostasis and causes the death of neuronal cells. Subsequently, infection of the brain stem may affect chemosensory neural cells associated with cardiorespiratory regulation, as well as neurons of the respiratory center. This damages the ventilatory lung function and exacerbates respiratory failure leading to profound hypoxia. A combination of hypoxia with existent neuroinflammation causes damage to the hippocampal and cortical areas resulting in the neuropsychiatric effects of the virus ${ }^{10}$.

- Immunological damage. The pathology of severe viral infections is closely linked to the development of systemic inflammatory response syndrome (SIRS). This syndrome could be abnormally initiated in severe pneumonia caused by SARS-CoV-2 infection. Therefore, COVID-19 has resulted in a large number of fatalities, most of which have been due to multiple organ dysfunction syndrome caused by virus-induced SIRS or SIRS-like immune disorders. The ability of this virus to infect macrophages, microglia, and astrocytes in the CNS has great importance since it allows SARS-CoV-2 to activate neuroglia and induce a pro-inflammatory state. SARS-CoV-2 infection of the CNS activates TCD4+ cells of the immune system. These, in turn, induce macrophages to secrete interleukin (IL) 6 by 
producing granulocyte-macrophage colony-stimulating factor. IL-6, a predominant component of cytokine storm syndrome in patients with COVID-19, has been positively correlated with increased severity of the disease. Furthermore, in vitro studies have shown that glial cells produce pro-inflammatory cytokines (IL-6, IL-12, IL-15, and tumor necrosis factor $\alpha$ ) after being infected by a coronavirus, which suggests a similar in vivo behavior. Activation of immune cells of the brain causes chronic inflammation and cerebral damage $\mathrm{e}^{2,9,11-13}$.

- ACE2 inhibition damage. ACE2 is a cardio-cerebral vascular protection factor that exists in a variety of organs, including the nervous system and skeletal muscles, playing a major role in regulating blood pressure and mechanisms of antiatherosclerosis. Since SARS-CoV-2 has high binding affinity to the ACE2 receptors, after binding to them it inhibits the enzyme and increases angiotensin II levels, which causes abnormally elevated blood pressure and increases the risk of a cerebral hemorrhage. In addition, given that the SARS-CoV-2 spike protein can interact with ACE2 expressed in the capillary endothelium, the virus may also damage the BBB and enter the CNS by attacking the vascular system. It has also been proposed that nicotine stimulation of the nicotinic acetylcholine receptors can increase ACE2 expression in neural cells, placing smokers at a higher risk for neurological complications by SARS-CoV-2 infection ${ }^{2,9-11}$.

- Other mechanisms. Biological properties of the CNS may facilitate exacerbation of the neurological damage caused by SARS-CoV-2 infection. The CNS has a dense parenchymal structure, and the usual lack of permeability of its blood vessels is a barrier to viral invasion. However, if a virus gains access to the CNS, it is difficult to remove. Due to the lack of major histocompatibility complex antigens in nerve cells, the elimination of viruses in those cells depends solely on the role of cytotoxic T cells; however, apoptosis of mature neurons after being infected also has a relatively protective effect. Furthermore, homeostatic features of cells in the CNS contribute to the continued existence of the virus ${ }^{9}$.

Hypotheses of neuroinvasiveness and neurovirulence of SARS-CoV-2, supported by the principles of causality enunciated by Bradford Hill in $1965^{14}$, are based on the following evidence: biological plausibility extrapolated from affectation of the CNS by other respiratory viruses, evidence of neurological damage produced by coronaviruses in other species, animal models of the CNS infection by human coronaviruses, the existence of neurological manifestations originated by other coronaviruses, and patients with COVID-19 that have experienced neurological complications ${ }^{6}$.

\section{COVID-19 and GBS}

GBS is caused by an abnormal autoimmune response against antigens (due to a preceding infection) that damage the gangliosides of peripheral nerves. It can deteriorate hastily, thus requiring high clinical suspicion, early identification, and appropriate management. In the past, also in the context of a viral disease outbreak, it has been pinpointed that Zika virus may be a risk factor for GBS. It is highly unknown if COVID-19 patients are also at high risk of GBS. However, the extensive evidence between Zika virus and GBS makes it relevant to study and decipher if COVID-19 is also associated with this peripheral neuropathy. SARS-CoV and Middle East respiratory syndrome coronavirus have both been associated with GBS as well ${ }^{3,5}$.

Zhao et al. reported GBS associated with COVID-19 in a 61-year-old woman, who presented acute weakness in both legs, and severe fatigue, progressing within a day. Neurological examination disclosed symmetric weakness Grade 4/5 (Medical Research Council [MRC] scale), and areflexia in both legs and feet. Three days after admission, muscle strength was Grade 4/5 in both arms and hands, and 3/5 in both legs and feet. Sensation to light touch and pinprick was decreased distally. Nerve conduction studies (day 5) showed delayed distal latencies and absent $F$ waves in early course, supporting demyelinating neuropathy. On day 8 , the patient developed a dry cough and a fever. Considering the temporal association, Zhao and collaborators speculate that SARS-CoV-2 infection might have been responsible for the development of GBS in this patient. Since the onset of GBS symptoms overlapped with the period of SARS-CoV-2 infection, they suggest that this peripheral neuropathy might have followed the pattern of a parainfectious profile, instead of the classic postinfectious one. This case is limited by the absence of microbiological testing on admission; therefore, it is prudent to consider the alternative explanation that the patient coincidentally developed GBS of unknown cause and acquired SARS-CoV-2 infection in a nosocomial manner (Table 1) $)^{15}$.

Virani et al. reported a 54-year-old male patient, with complaints of numbness and lower-limb weakness of 2-day duration. The patient reported having a fever and a non-productive cough of 10-day duration that did not improve with a short course of oral amoxicillin 


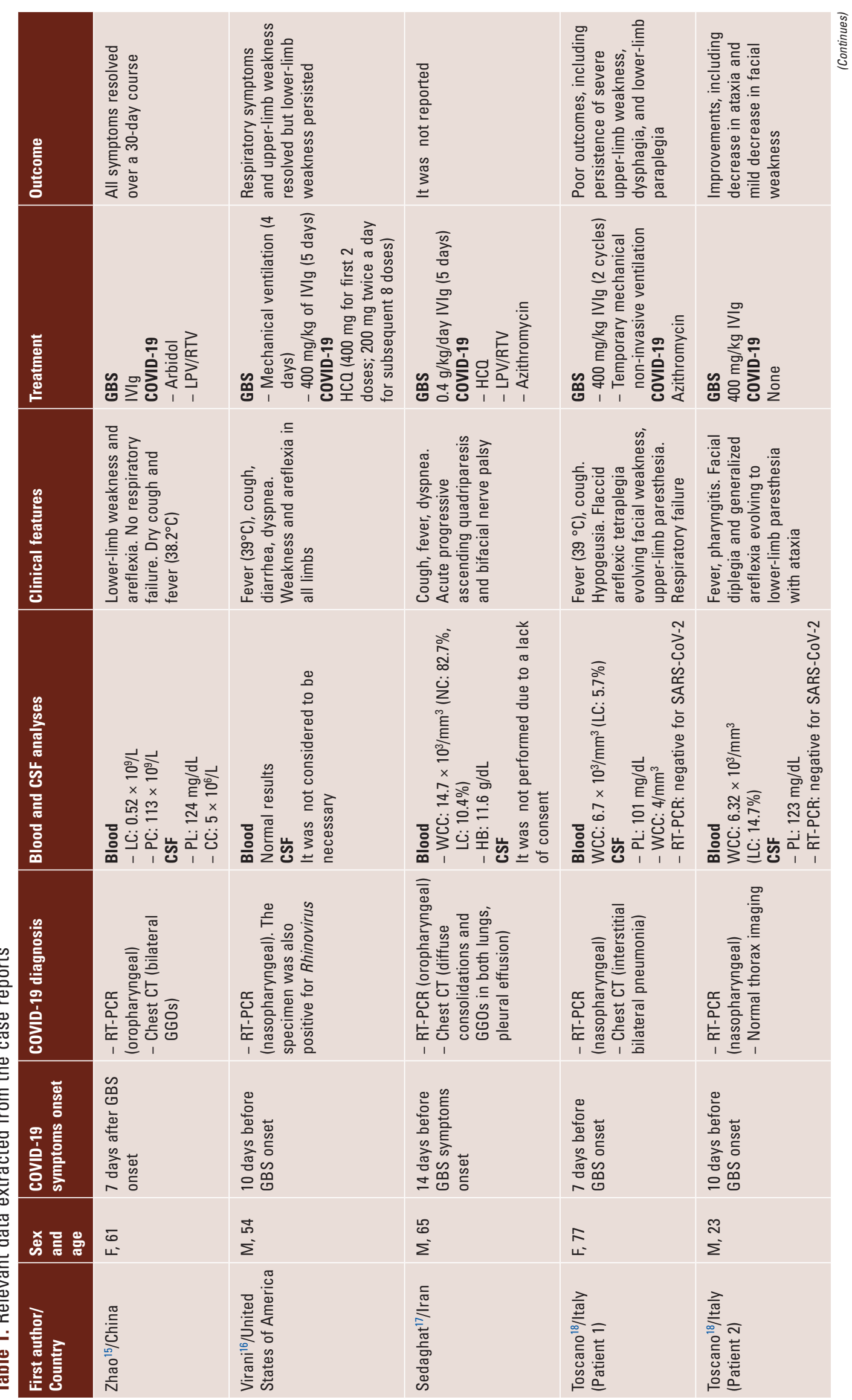



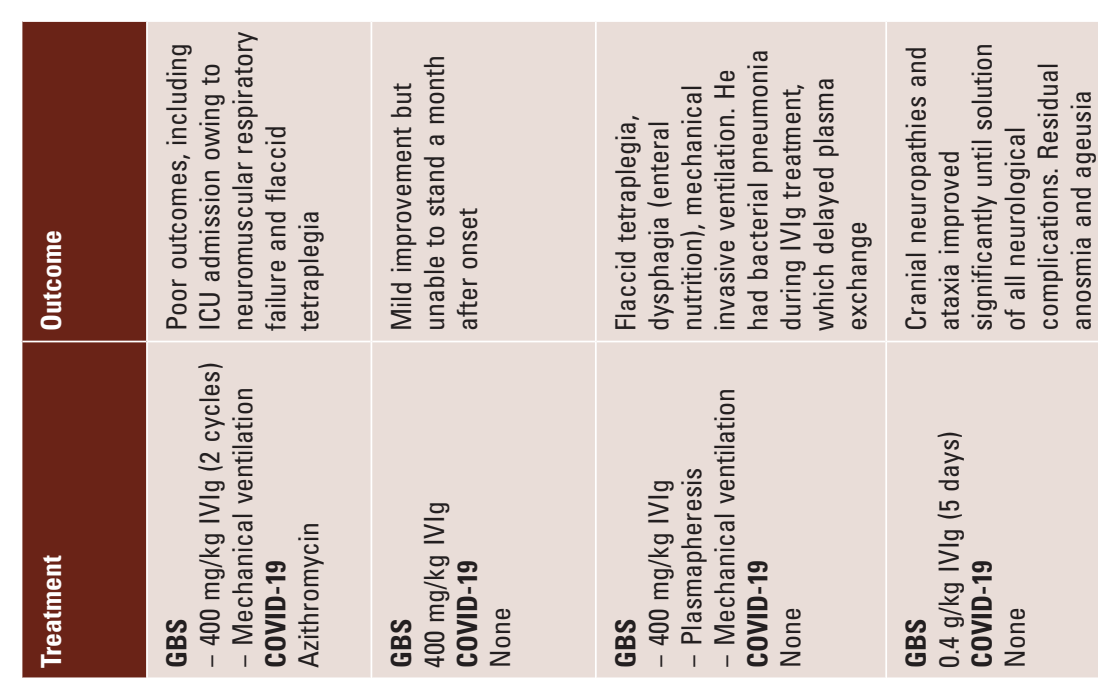

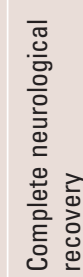
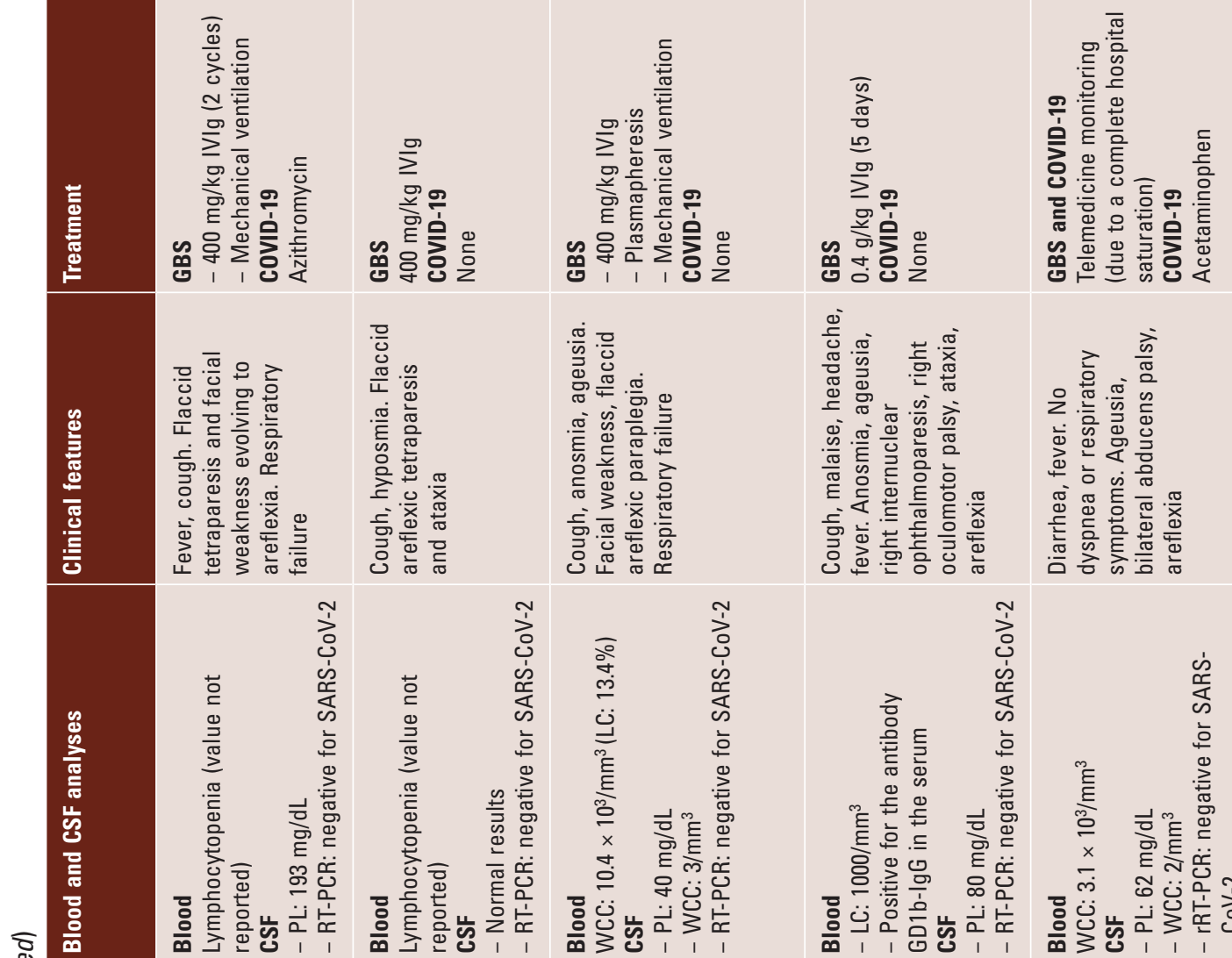

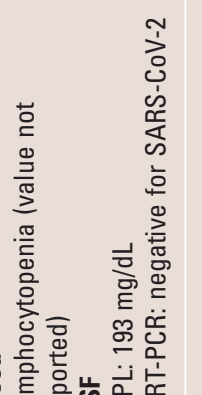

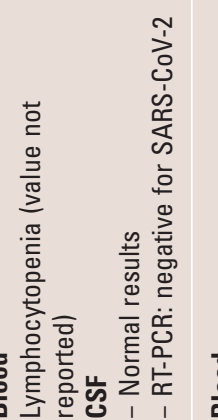

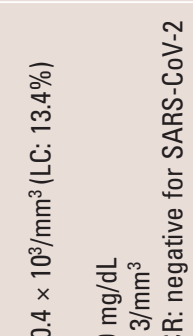

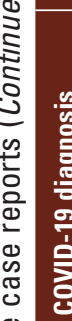

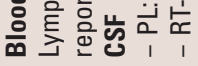

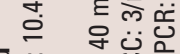

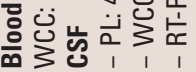

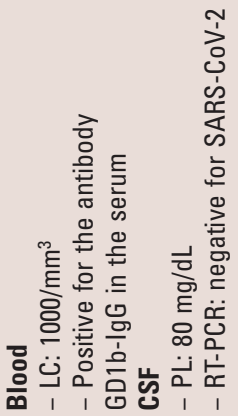
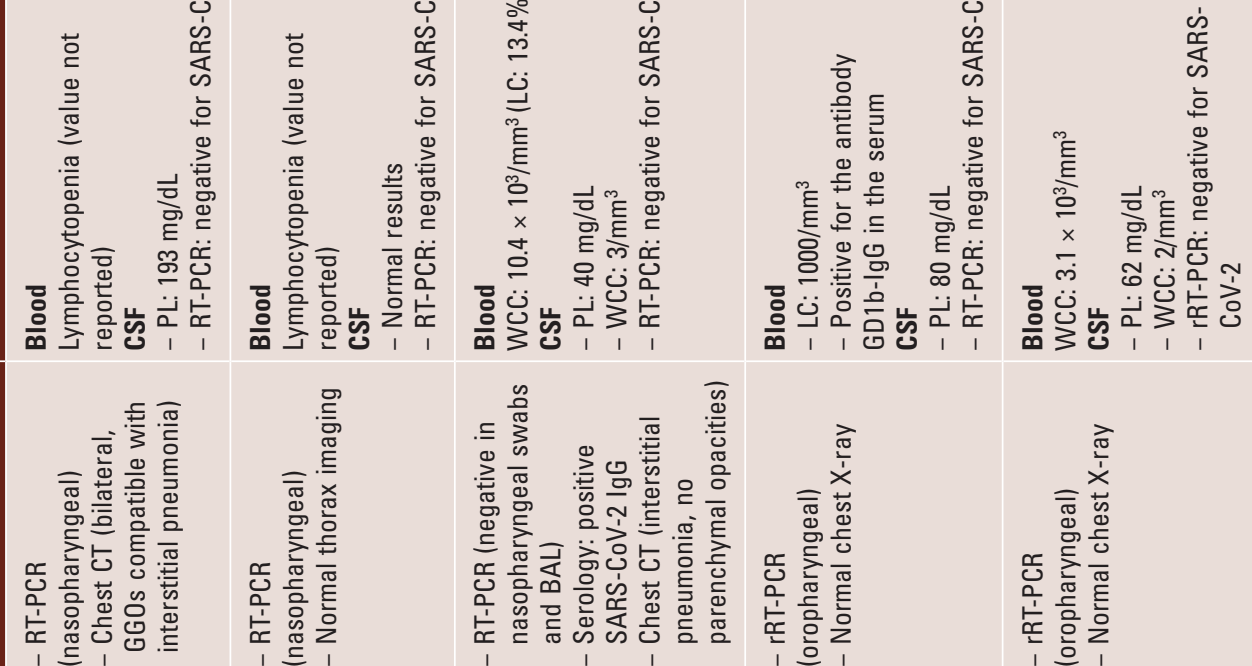

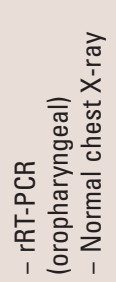

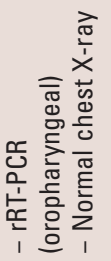

巳
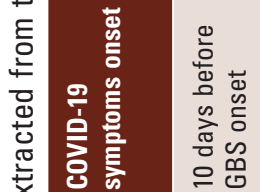

施

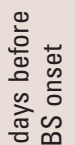

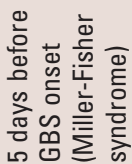

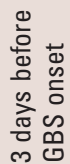

要

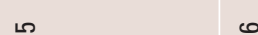

\begin{tabular}{l|l}
2 & $\overline{0}$ \\
$\Sigma$ & $\Sigma$
\end{tabular}

s.

$\stackrel{\text { m}}{\Sigma}$

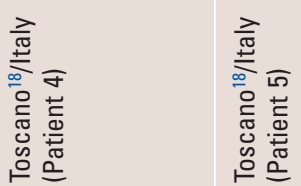

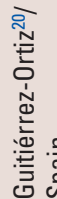

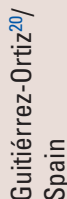




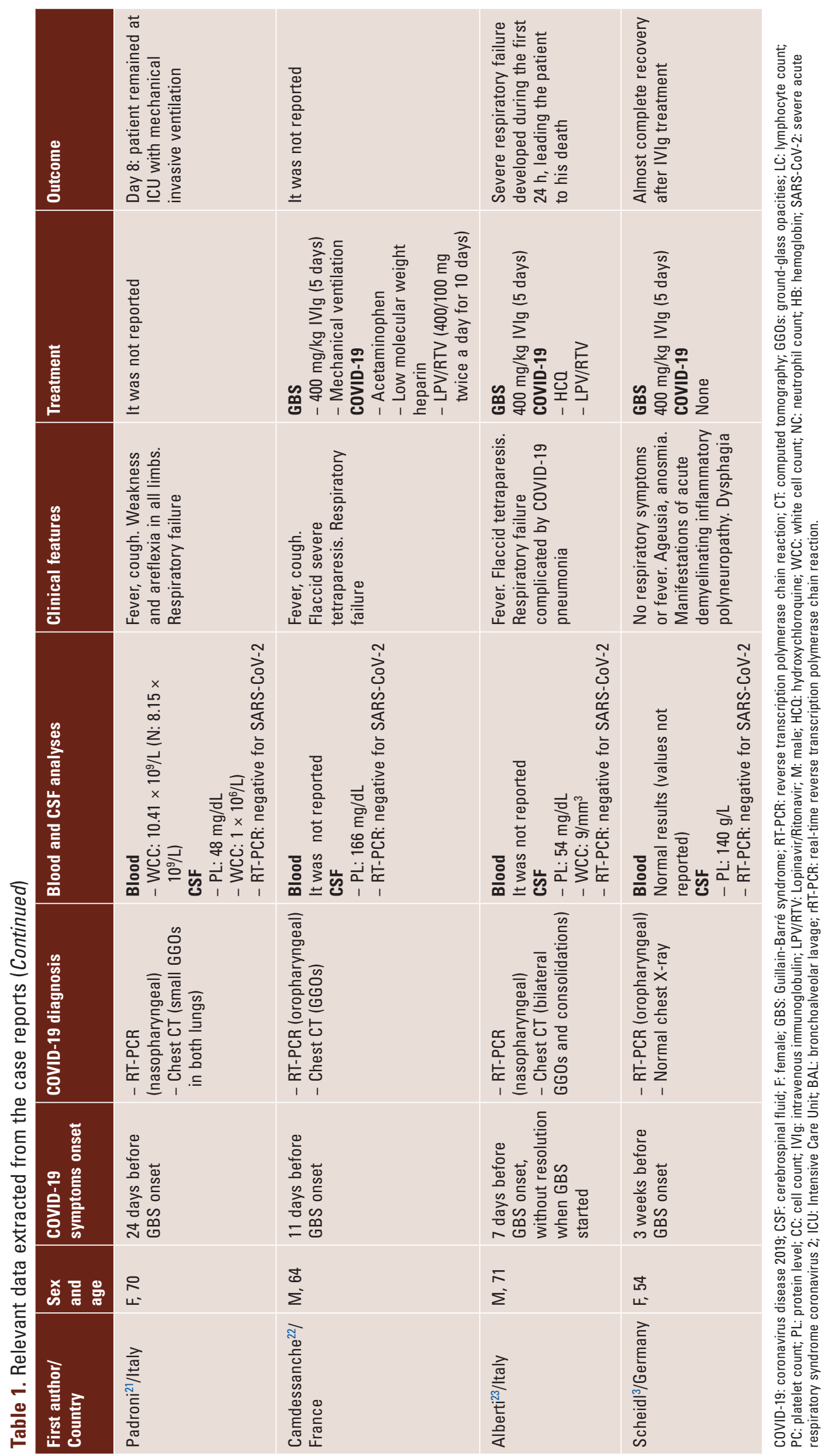


and steroids. He subsequently developed diarrhea due to Clostridium difficile colitis that had been diagnosed 2 days before (symptoms improved after starting on treatment). While still undergoing initial workup, the patient reported urinary retention, prompting magnetic resonance imaging (MRI) of the thoracic, and lumbar spine (incidental findings of bilateral basilar opacities in the lungs were only revealed). He was evaluated by the neurology team and noted to have 2/5 strength in his lower limbs, with $3 / 5$ in his upper limbs, according to the MRC scale. Deep tendon reflexes (DTRs) were absent. A diagnosis of GBS was made $(\text { Table } 1)^{16}$.

Sedaghat et al. reported a 65-year-old male patient who was admitted with symptoms of acute progressive symmetric ascending quadriparesis. Neurological manifestations of the patient began with acute progressive weakness of distal lower limbs, 5 days before admission. At that time, symptoms progressed from distal to proximal limbs, until the onset of quadriplegia a day before admission. There was bilateral facial paresis as well. Two weeks before hospitalization, the patient had had a cough, a fever, and sometimes suffered from dyspnea. The patient was a well-known case of type 2 diabetes mellitus, treated with metformin medication. Muscle strength examination showed weakness in the four limbs with an MRC scale of 2/5 in proximal and $3 / 5$ in distal upper limbs; and $1 / 5$ in proximal and 2/5 in distal lower limbs. DTRs were absent. There was a reduction in the vibration and fine touch sensation distally to the ankle joints, and also bifacial nerve palsy (House-Brackmann Grade 3). On day 9, the neurophysiological study delayed acute motor-sensory axonal neuropathy (Table 1$)^{17}$.

From February 28 to March 21, 2020, in three hospitals in Northern Italy, five patients who had GBS after the onset of COVID-19 were examined. Toscano et al. reported that the first symptoms of GBS were lower-limb weakness and paresthesia in four patients, and facial diplegia, followed by ataxia and paresthesia in one patient. Generalized, flaccid tetraparesis or tetraplegia evolved over a period of $36 \mathrm{~h}$ to 4 days in four patients; three patients received mechanical ventilation. The results of electrophysiological studies showed that compound muscle action potential amplitudes were low but could be obtained; two patients had prolonged motor distal latencies. On electromyography, fibrillation potentials were present in three patients initially. In another patient, they were absent initially but later present at 12 days. The findings were generally consistent with an axonal variant of GBS in three patients, and with a demyelinating process in two patients. MRIs, performed with administration of gadolinium, showed enhancement of caudal nerve roots in two patients, enhancement of the facial nerve in one patient, and no signal changes in nerves in two patients. This observational series could not determine whether severe deficits and axonal involvement are typical features of COVID-19-associated GBS (Table 1) $)^{18,19}$.

Guitiérrez-Ortiz and collaborators reported two male patients, who were 50 and 39 years old, respectively. The first one was admitted because of a 2-day history of vertical diplopia, perioral paraesthesia, and gait instability. His medical history was remarkable for bronchial asthma. Five days prior, he had developed a cough, malaise, a headache, low-back pain, and a fever. Neurological examination revealed: absent DTRs in upper and lower limbs, right internuclear ophthalmoparesis, and right fascicular oculomotor palsy. These findings were consistent with Miller-Fisher syndrome (a variant of GBS). The youngest patient, on the other hand, presented acute-onset diplopia. Three days before, he had presented diarrhea, a low-grade fever, and a generally poor condition, without any headache, respiratory symptoms, or dyspnea. He did not report nausea or vomiting but noted the presence of ageusia. He was diagnosed with polyneuritis cranialis (another variant of GBS). Neurological examination showed generalized absence of DTRs, as well as bilateral abducens palsy $(\text { Table } 1)^{20}$.

Padroni et al. reported a 70-year-old woman who complained of asthenia, hands, and feet paresthesia, and gait difficulties progressing within a day. Twenty-four days prior, she had developed a fever and a dry cough. Neurological examination disclosed moderate (MRC scale: 4/5) symmetric distal upper and lower-limb weakness, loss of DTRs, and preserved light touch and pinprick sensation. Neurophysiologic findings were consistent with a diagnosis of GBS (Table 1$)^{21}$.

Camdessanche et al. described the case of a 64-yearold French man who was admitted after he fell and hurt his left shoulder leading to a tear of the rotator cuff. He had a fever and a cough for 2 days. Eleven days after, the patient complained of paresthesia in feet and hands. In 3 days, he showed flaccid severe tetraparesis. MRC strength evaluation was $2 / 5$ in legs, $2 / 5$ in arms, $3 / 5$ in forearms, and $4 / 5$ in hands. DTRs were abolished in the four limbs. Five days after neurological symptom onset, electrodiagnostic tests disclosed a demyelinating pattern in accordance with GBS $(\text { Table } 1)^{22}$. 
Alberti et al. reported a 71-year-old male patient with subacute onset of paresthesia at limb extremities, followed by distal weakness rapidly evolving to severe, flaccid tetraparesis over the previous 3 days. He had had a low-grade fever for few days the week prior. Relevant conditions in his medical history included hypertension, abdominal aortic aneurysm treated with endovascular repair in 2017, and lung cancer exclusively treated with surgery. Neurological examination showed: symmetric limb weakness (MRC scale: $3 / 5$ in upper limbs and 2/5 in lower limbs), symmetric and extensive stocking-glove hypoesthesia in the four limbs (more pronounced in lower limbs), and absent DTRs. The patient complained of severe paresthesia in both hands and feet. Moderate dyspnea and moderate low-back pain were present at the time of the first evaluation. He showed hemodynamic disturbances with severe drug-resistant hypertension. Electrodiagnostic tests disclosed a severe form of acute polyradiculoneuritis with prominent demyelinating features (Table 1$)^{23}$.

In Germany, Scheidl et al. reported a 54-year-old woman with typical clinical and electrophysiological manifestations of acute demyelinating inflammatory polyneuropathy (the most common type of GBS in Europe). She did not experience a preceding fever or respiratory symptoms, but a transient loss of smell and taste was present. At the moment of admission, a progressive proximally-pronounced paraparesis, areflexia, and sensory loss with tingling in all limbs were found, which had begun 10 days before. The modified Erasmus GBS outcome score was $3 / 9$ at admission and $1 / 12$ on day 7 of hospitalization. The electrophysiological assessment proved a segmental demyelinating polyneuropathy (Table 1$)^{3}$.

\section{Conclusions}

GBS is emerging as a relevant neurological complication in COVID-19 patients, though their association is still to be proven by more in-depth studies. While the current evidence is not enough to confirm a causal relationship between COVID-19 and GBS, it does justify the verisimilitude of such association, which does not seem to be a fortuitous one. Future studies on the physiopathology and clinical/electrophysiological features of the COVID-19-associated GBS will provide biomedical personnel with a more complete understanding of the performance of GBS in patients with COVID-19 as well as information regarding how to successfully treat it.

\section{Acknowledgments}

The author wishes to thank Dr. Hector Vera Cuesta, Dr. Yordanka Cuza Ferrer, Dr. Miguel Felipe Miranda Ación, and Mr. Jarod Hudson for the valuable advice they provided to this work.

\section{Funding}

None.

\section{Conflicts of interest}

This research has not received any specific grant from public, commercial, or nonprofit agencies.

\section{Ethical disclosures}

Protection of human and animal subjects. The authors declare that no experiments were performed on humans or animals for this study.

Confidentiality of data. The authors declare that no patient data appear in this article.

Right to privacy and informed consent. The authors declare that no patient data appear in this article.

\section{References}

1. León Castellón R, Bender Del Busto JE, Velázquez Pérez LC. Afectación del sistema nervioso por la COVID-19. An Acad Cienc Cuba. 2020;10:e760.

2. Lahiri D, Ardila A. COVID-19 pandemic: a neurological perspective. Cureus. 2020;12:e7889.

3. Scheidl E, Canseco DD, Hadji-Naumov A, Bereznai B. Guillain-Barre syndrome during SARS-CoV-2 pandemic: a case report and review of recent literature. J Peripher Nerv Syst. 2020;25:204-7.

4. Rana S, Lima AA, Chandra R, Valeriano J, Desai T, Freiberg W, et al. Novel coronavirus (COVID-19)-associated Guillain-Barré syndrome: case report. J Clin Neuromuscul Dis. 2020;21:240-2.

5. Carrillo-Larco RM, Altez-Fernandez C, Ravaglia S, Vizcarra JA. COVID-19 and Guillain-Barre syndrome: a systematic review of case reports. Wellcome Open Res. 2020;5:107.

6. Carod-Artal FJ. Complicaciones neurológicas por coronavirus y COVID-19. Rev Neurol. 2020;70:311-22.

7. Berger JR. COVID-19 and the nervous system. J Neurovirol. 2020;26:143-8.

8. Motalvan V, Lee J, Bueso T, De Toledo J, Rivas K. Neurological manifestations of COVID-19 and other coronavirus infections: a systematic review. Clin Neurol Neurosurg. 2020;194:105921.

9. Wu Y, Xu X, Chen Z, Duan J, Hashimoto K, Yang L, et al. Nervous system involvement after infection with COVID-19 and other coronaviruses. Brain Behav Immun. 2020;87:34-9.

10. Sheraton M, Deo N, Kashyap R, Surani S. A review of neurological complications of COVID-19. Cureus. 2020;12:e8192.

11. Ahmed MU, Hanif M, Ali MJ, Haider MA, Kherani D, Memon GM, et al. Neurological manifestations of COVID-19 (SARS-CoV-2): a review. Front Neurol. 2020;11:518

12. Ahmad I, Rathore FA. Neurological manifestations and complications of COVID-19: a literature review. J Clin Neurosci. 2020;77:8-12.

13. Bridwell R, Long B, Gottlieb M. Neurologic complications of COVID-19. Am J Emerg Med. 2020;38:1549.

14. Ellul M, Varatharaj A, Nicholson TR, Pollak TA, Thomas N, Easton A, et al. Defining causality in COVID-19 and neurological disorders. J Neurol Neurosurg Psychiatry. 2020;91:811-2.

15. Zhao $H$, Shen $D$, Zhou $H$, Chen S. Guillain-Barré syndrome associated with SARS-CoV-2 infection: causality or coincidence? Lancet Neurol. 2020;19:383-4. 
Rev Mex Neuroci. 2020;21(5)

16. Virani A, Rabold E, Hanson T, Haag A, Elrufay R, Cheema T. Guillain-Barré Syndrome associated with SARS-CoV-2 infection. IDCases. 2020;20:e00771.

17. Sedaghat Z, Karimi N. Guillain Barre syndrome associated with COVID-19 infection: a case report. J Clin Neurosci. 2020;76:233-5

18. Toscano G, Palmerini F, Ravaglia S, Ruiz L, Invernizzi P, Cuzzoni MG et al. Guillain-Barré syndrome associated with SARS-CoV-2. N Engl J Med. 2020;382:2574-6.

19. Bender Del Busto JE, León Castellón R, Mendieta Pedroso MD, Rodríguez Labrada R, Velázquez Pérez LC. Infección por el SARS-CoV-2: de los mecanismos neuroinvasivos a las manifestaciones neurológicas. An Acad Cienc Cuba. 2020;10:e855.
20. Gutiérrez-Ortiz C, Méndez-Guerrero A, Rodrigo-Rey S, Pedro-Murillo ES, Bermejo-Guerrero L, Gordo-Mañas R. Miller Fisher syndrome and polyneuritis cranialis in COVID-19. Neurology. 2020;95:e601-5.

21. Padroni M, Mastrangelo V, Asioli GM, Pavolucci L, Abu-Rumeileh S, Piscaglia MG. Guillain-Barré syndrome following COVID-19: new infection, old complication? J Neurol. 2020;267:1877-9.

22. Camdessanche JP, Morel J, Pozzetto B, Paul S, Tholance Y, Botelho-Nevers E. COVID-19 may induce Guillain-Barre syndrome. Rev Neurol (Paris). 2020;176:516-8

23. Alberti $P$, Beretta S, Piatti M, Karantzoulis A, Piatti ML, Santoro P, et al. Guillain-Barre syndrome related to COVID-19 infection. Neurol Neuroimmunol Neuroinflamm. 2020;7:e741. 